\title{
USE OF VIRTUAL REALITY FOR THE THERAPY OF PENSIONERS WITH COMMUNiCATION DisORDERS
}

\author{
Ivan Kovar, Miroslav Musalek
}
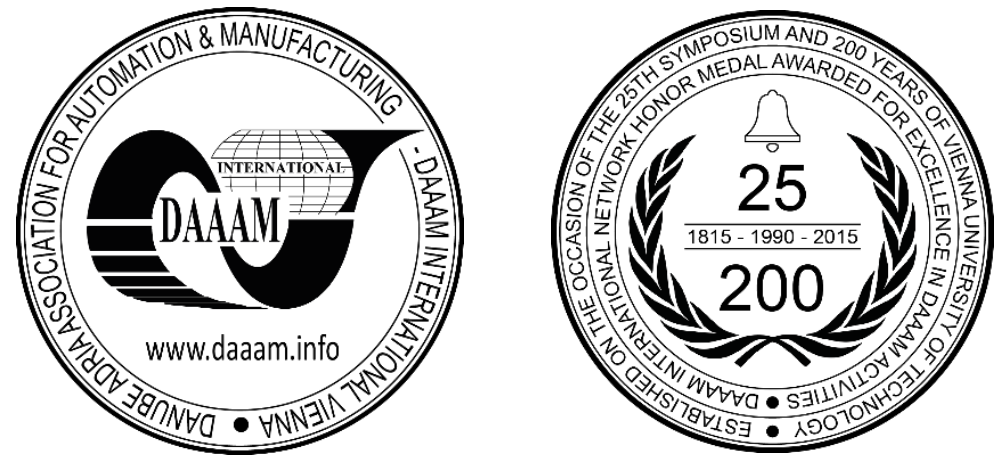

This Publication has to be referred as: Kovar, I[van] \& Musalek, M[iroslav] (2018). Use of Virtual Reality for the Therapy of Pensioners with Communication Disorders, Proceedings of the 29th DAAAM International Symposium, pp.0811-0816, B. Katalinic (Ed.), Published by DAAAM International, ISBN 978-3-902734-20-4, ISSN 1726-9679, Vienna, Austria

DOI: $10.2507 / 29$ th.daaam.proceedings. 117

\begin{abstract}
The subject of this article is to find out if there is any possibility that virtual reality can help to heal the people with social anxiety disorder. The aim of the suggested and realized pre-research was to train people in effectively coping with situations they are afraid of, systematically boosting positive thinking and weakening negative mindsets in order to enable people to enjoy a better quality of life without using medication. We organized a pre-research with use of HTC Vive virtual reality device on a small sample of examined respondents with social anxiety disorder in communication skills. Initial results are obtained from questionnaire methods of two type of specialized tests (SPIN and MCQ30). Graphs show improvement of mental state of respondents in case of use new modern methods, especially virtual reality.
\end{abstract}

Keywords: social anxiety; Cognitive Behavioral Therapy; virtual reality; HTC Vive

\section{Introduction}

This article focuses on the use of virtual reality (VR) in treating people, especially pensioners with social anxiety disorder in the field of communication. Social anxiety disorder (SAD) is one of the most common psychiatric disorders with a lifetime prevalence of between $7 \%$ and $13 \%$ on the European continent [1].

The aim of the pre-research was to train people in effectively coping with situations they are afraid of, systematically boosting positive thinking and weakening negative mindsets in order to enable people to enjoy a better quality of life without using medication. The patients are often given combined treatment (pharmacotherapy together with cognitive-behavioural therapy), which can accelerate the recovery process. However, there is speculation concerning the adverse effects of pharmaceuticals, as using medication to reduce the intensity of anxiety does not necessarily result in successful cognitive changes, i.e. the person does not learn to completely resist anxiety [2]. Therefore, the pre-research strives to work with modern and developing technologies to accelerate the therapy process without medication. The pre-research worked with two pensioners who had undergone special tests to examined their social anxiety disorder symptoms. Then respondent two continued to attend just the normal sessions with a psychologist. The respondent one, besides the psychology sessions, was also attending therapy sessions using virtual reality. This provided a space for creating an anxiety situation that can be worked with. 
After 10 sessions, they changed their positions. The respondent two started to attend normal psychologist sessions as well as therapy sessions using virtual reality. The respondent one visited only normal psychologist sessions. There were totally 20 sessions.

\section{Material and methods}

\subsection{Virtual reality}

Virtual reality may be described as a computer system that creates a computer-generated imaginary environment. [3] This pre-research worked with the HTC Vive virtual reality system. In addition to VR, there is widespread reality and these differences are described in the article [4].

Components of the HTC Vive: The HTC Vive virtual reality system consists of several parts (Fig. 1.), which, when linked up, take a person into another reality. The main component is the headset (component 1 - in Fig. 1.), to be worn on the head. This is the main part that displays the 3D image. Connected to the headset are headphones which create a more realistic impression of being in a different dimension. There can be used whatever headphones with $3.5 \mathrm{~mm}$ jack connector. The set also includes two controllers (component 2 - in Fig. 1.), one for each hand, which one uses to control one's movement in the application. Each controller contains a series of buttons offering a wide variety of controls. The set also contains two Base Stations (component 3 - in Fig. 1.), which sense the person's position and transmit it into the virtual world. The stations therefore need to be placed so that they sense the user from each side. The Link Box (component 4 - in Fig. 1.) connects the HTC Vive headset with a computer. The Link Box is powered by the power supply (included) plugged into the mains socket. The set also includes cables, some for powering the controllers and others for connecting the stations to the power supply.

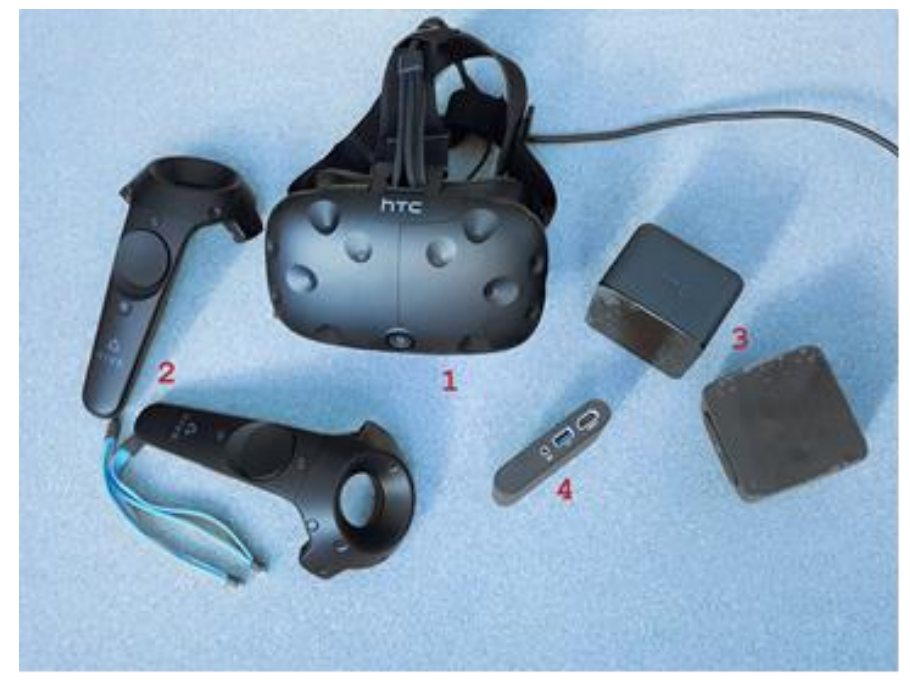

Fig. 1. Components of HTC Vive (1-Headset, 2-Controllers, 3-Base Stations, 4-Link Box)

For the HTC Vive to work properly one needs a well-equipped computer system with a powerful graphics card. Our test set consisted of Intel Core i7 7700 Kabylake 4.2GHz, Intel B250, RAM 16GB DDR4, NVIDIA GeForce GTX1080Ti 11GB, SSD 240GB + HDD 2000GB, Windows 10 64-bit.

\subsection{Social anxiety disorder}

This is a mental disorder where the person experiences unpleasant feelings when in contact / thinking about contact with people and strives to avoid such situations. The main concern with social anxiety phobia is the fear of failure, inability to cope with situations, being ridiculed or criticized by others. The characteristic symptom of such behavior is an effort to avoid situations which could induce anxiety, even if doing so would have negative consequences. Despite the fact that the person with the social phobia generally realizes that their anxiety symptoms are unfounded, they are often unable to suppress them in a particular situation, which leads to further feelings of inadequacy, embarrassment and failure. Their negative thoughts are about themselves. Social anxiety phobia is not a serious mental disorder, although in the long term it can restrict the sufferer, as in today's society it is not possible to avoid communicating with people or having to perform in the presence of others $[5,6]$.

An estimated 3 to $13 \%$ of the world's population suffers from social anxiety phobia at some time during their lives. $1-3$ $\%$ of people suffer social anxiety disorder all their lives. This phobia of social situations generally emerges around puberty, most often somewhere between the ages of 14 to 20 [7]. 
Most common manifestations of social anxiety disorder are fear of:

- $\quad$ being the center of attention;

- $\quad$ speaking in front of an authority, group, at social gatherings;

- $\quad$ eating in front of people;

- $\quad$ saying no or asking for something we need and are entitled to;

- $\quad$ using public toilets;

- being looked at by others;

- disablement;

- one's own unnatural behaviour;

- $\quad$ writing in public (signing one's name at the post office, filling in forms);

- using the telephone;

- $\quad$ starting and continuing conversation;

- $\quad$ avoidance of social situations [7].

Typical physical manifestations of social anxiety disorder include trembling hands and body, blushing, sweating, heart palpitations, nausea, tightness of the throat, the sensation of having difficulty breathing, feeling faint, etc. The possible consequences of social anxiety disorder include loneliness, dependence on one's parents, learning problems, problems at work, alcohol and drug addiction, periods of depression, and, in extreme cases, attempted suicide [7].

Effective means of treating social anxiety disorder include cognitive behavioural therapy (CBT) and treatment with antidepressants (particularly if the patient also has another anxiety disorder, or depression). Cognitive-behavioural procedures in the treatment of social phobia involve practising ways of effectively coping with feared situations, systematically boosting positive thinking and weakening negative mindsets [8].

\section{Methods of measuring anxiety}

Social Phobia Inventory (SPIN): The SPIN method is used to measure social anxiety / concern, fear, physiological symptoms and avoidance of social situations. The SPIN test contains 17 questions and is divided up into three categories according to the following factors: fear, avoidance and avoidance symptoms. Each of the 17 questions is evaluated on a scale of 0 to $4(0=$ not at all, $1=$ a little, $2=$ partially, $3=$ often, $4=$ completely $)$. The total score ranges from 0 to 68, with a higher score indicating a higher degree of anxiety [9].

Metacognition Questionnaire - 30 (MCQ-30): The MCQ-30 questionnaire evaluates the individual differences in five factors that are important in the metacognitive model of mental disorders. Poor metacognition in particular may encourage obsessive and compulsive symptoms, pathological concerns and promote manifestations of anxiety. These 5 factors are cognitive confidence, positive beliefs about worry, cognitive self-consciousness, negative beliefs about uncontrollability and danger and the need to control thoughts. The score of each factor ranges from 6 to 24 points and the total score ranges from 30 to 120 , with a higher score indicating a higher degree of inappropriate metacognitions $[10]$.

\section{Results and discussions}

\subsection{Experimental pre-research}

We have questioned whether virtual reality can be useful in the healing process of people, especially pensioners. The propone experiment can find the answer on our question. The pre-research was conducted from March to the end of April 2018 at the Faculty of Applied Informatics at Tomas Bata University in Zlin on a small sample of respondents.

The experiment worked with two pensioners suffering from social anxiety disorder, specifically in connection with communication skills. Both had problems communicating fluently in front of strangers, felt nervous, a tightness in the throat, nausea, or were unable to speak coherently.

The pre-research focuses particularly on manifestations of communication and on improving verbal skills and the reframing of thought processes. People suffering from this disorder mostly picture the catastrophic scenarios of their actions. These thoughts make them even more stressed, affecting their communication accordingly. One example is the fear of speaking to a stranger in the street in order to obtain information.

The suffers imagine in advance that they will blush when they speak, will start to stutter and will seem incompetent, and so either do not speak to anyone at all, or what they have imagined actually happens due to their high stress level. This reinforces their ideas about themselves and they will be afflicted by the same thoughts next time. The pre-research thus works with similar situations, where people train their communication skills and thus strengthen positive thoughts. Basic information about the people involved in the pre-research can be seen in Table 1. 


\begin{tabular}{|c|c|c|}
\hline & $\begin{array}{c}\text { Respondent } \\
1\end{array}$ & $\begin{array}{c}\text { Respondent } \\
2\end{array}$ \\
\hline G ender & Male & Male \\
\hline Age & 59 & 64 \\
\hline Medication & No & No \\
\hline Level of ecucation & University & $\begin{array}{c}\text { High } \\
\text { school }\end{array}$ \\
\hline $\begin{array}{c}\text { Approximate year in which } \\
\text { they first experienced arxiety }\end{array}$ & 1979 & 1972 \\
\hline
\end{tabular}

Table 1. Overview of general data of the people involved in the pre-research

The experiment was realized as follow: Respondent two continuing to attend only the normal psychological sessions with a psychologist. The respondent one, besides the psychology sessions, also attending therapy sessions using virtual reality. After 10 sessions, they changed their positions. The respondent two started to attend normal psychologist sessions as well as therapy sessions using virtual reality. The respondent one visited only normal psychologist sessions.

At the start of each therapy session the individuals were told about the situation they would undergo. At the beginning they had time to think, while in later sessions they were put straight into the situation. After the completion of each situation there was an opportunity to hear feedback from an expert. At the end of each session, there was 15 minutes' relaxation phase, designed to help the people relax and ease their stress and nerves. Virtual reality was used to create an anxiety environment, in which the individuals practiced their communication skills and their ability to cope with anxiety as can be seen in Fig. 2. During each session, they each underwent the similar phases.

There were totally 20 sessions, 10 VR sessions with each of the two participants. The anxiety tests were done every fifth session so there were done totally 5 times. At the end, there was an evaluation of the results, which clearly shows that the individual who used virtual reality has improved social anxiety and demonstrates the efficiency of the new method with virtual reality.

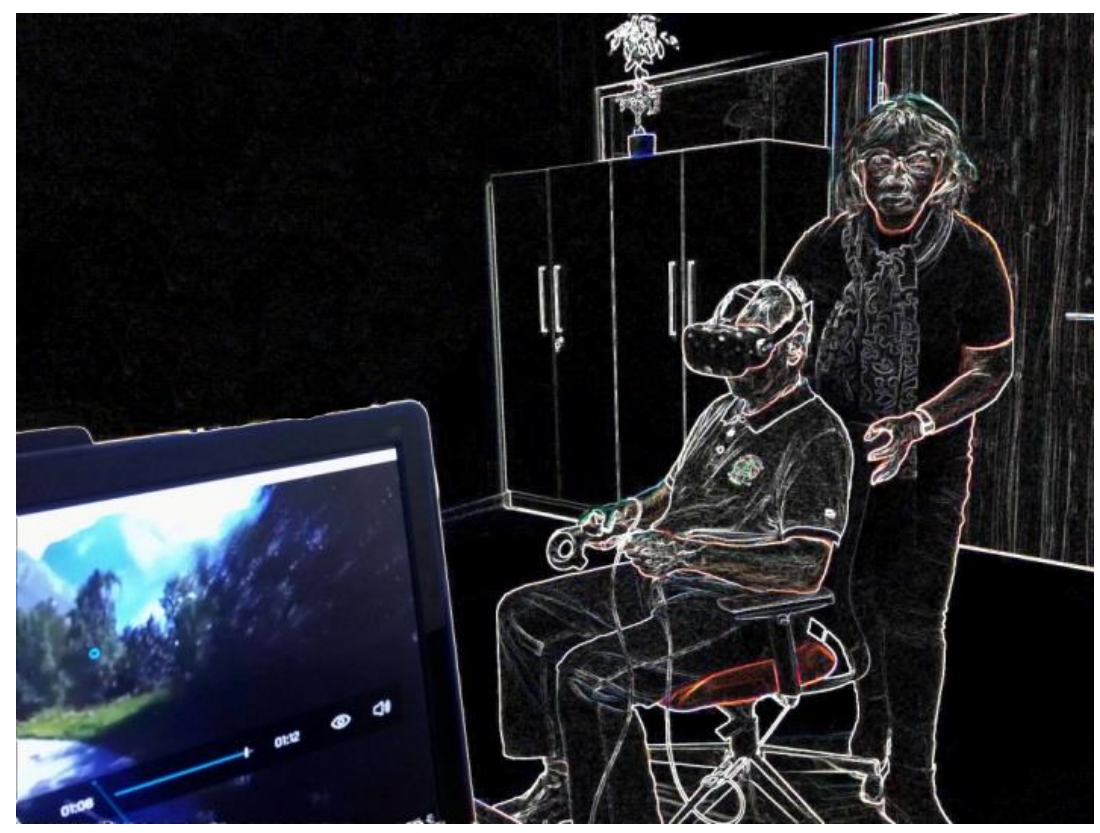

Fig. 2. Individual during the course of the therapy

\subsection{Summary of Pre-Research}

At the first, fifth, tenth, fifteenth and twentieth session of the pre-research, all the participants underwent the same process, during which they filled in tests measuring their level of anxiety. We used tests, covering two methods, as it was mentioned above: Social phobia inventory (SPIN test), Metacognition Questionnaire-30 (MCQ-30). The gained results from the measurements can be seen in Table 2 . 


\begin{tabular}{|c|c|c|c|c|c|c|}
\hline & & $\begin{array}{c}\text { Session } \\
1\end{array}$ & $\begin{array}{c}\text { Session } \\
5\end{array}$ & $\begin{array}{c}\text { Session } \\
10\end{array}$ & $\begin{array}{c}\text { Session } \\
15\end{array}$ & $\begin{array}{c}\text { Session } \\
20\end{array}$ \\
\hline \multirow{3}{*}{ SPIN } & Resp. 1 & $\begin{array}{c}59 \\
(\mathrm{VR})\end{array}$ & $\begin{array}{c}52 \\
(\mathrm{VR})\end{array}$ & $\begin{array}{c}47 \\
(\mathrm{VR})\end{array}$ & 45 & 44 \\
\cline { 2 - 7 } & Resp. 2 & 57 & 55 & 52 & $\begin{array}{c}46 \\
(\mathrm{VR})\end{array}$ & $\begin{array}{c}40 \\
(\mathrm{VR})\end{array}$ \\
\hline \multirow{2}{*}{$\begin{array}{c}\text { MCQ } \\
-30\end{array}$} & Resp. 1 & $\begin{array}{c}102 \\
(\mathrm{VR})\end{array}$ & $\begin{array}{c}91 \\
(\mathrm{VR})\end{array}$ & $\begin{array}{c}83 \\
(\mathrm{VR})\end{array}$ & 79 & 74 \\
\cline { 2 - 7 } & Resp. 2 & 97 & 93 & 89 & $\begin{array}{c}78 \\
(\mathrm{VR})\end{array}$ & $\begin{array}{c}70 \\
(\mathrm{VR})\end{array}$ \\
\hline
\end{tabular}

Table 2. Results of measurement (Respondent $=$ Resp.)

Fig. 3. and Fig. 4. represent gained results in graphical form, where can be seen values of individual measurements of anxiety tests and its symptoms. From the gained results can be deduced that the person who was using also VR therapy had a bigger shift to better results than a person who only attended normal psychological sessions at that time. A significant change in curve shape occurred when the conditions changed for both.

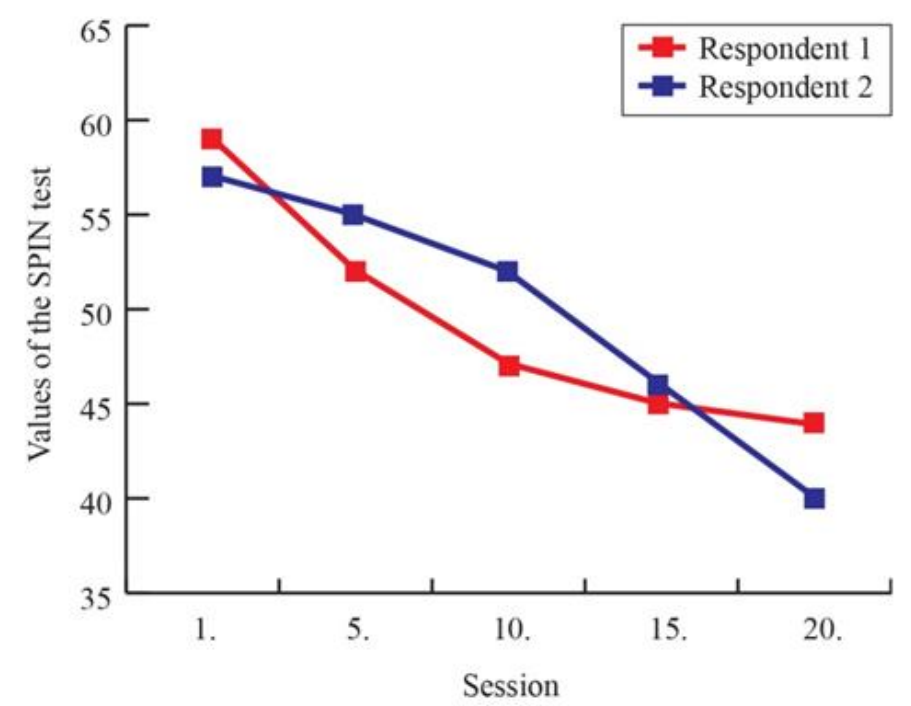

Fig. 3. Results of measurement of SPIN method - respondent 1 (1-10 session with VR, 1120 session without VR), respondent 2 (1-10 session without VR, 11-20 session with VR)

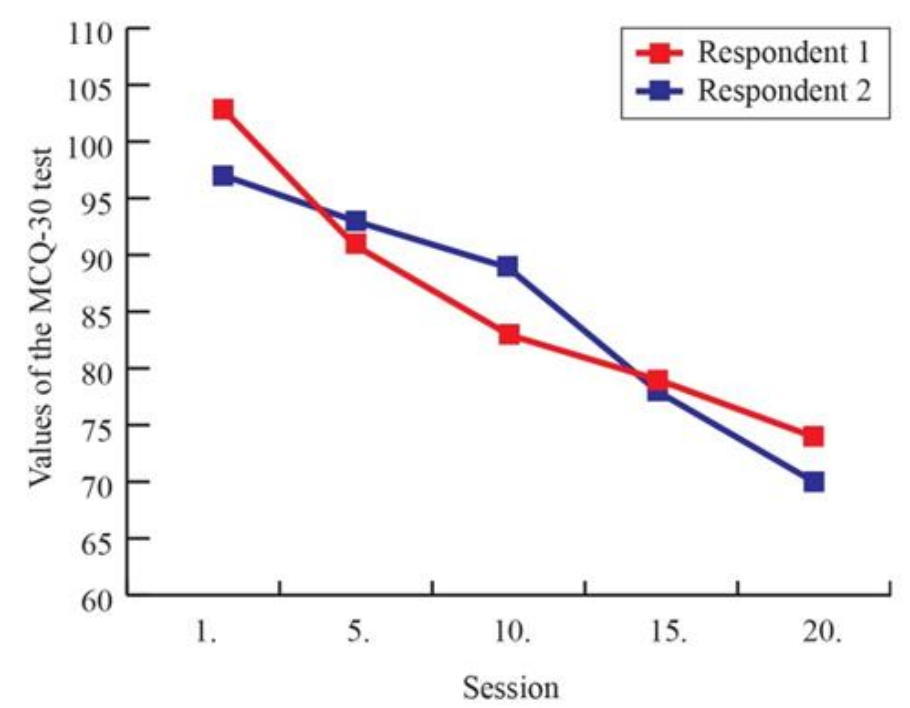

Fig. 4. Results of measurement of MCQ - 30 - respondent 1 (1-10 session with VR, 11-20 session without VR), respondent 2 (1-10 session without VR, 11-20 session with VR) 
These data show that virtual reality positively affects the mental state of people. This positive effect affects the time and regularity of virtual reality. Using VR does not only have positive effects but also has its negative side. Users can become addicted to it. In an incorrectly chosen procedure and environment, the mental state of people may deteriorate.

\section{Conclusion}

The primary aim of the pre-research was to determine whether virtual reality can be used as part of cognitivebehavioral therapy for people, especially pensioners suffering from social anxiety disorder, specifically in terms of their communication skills. The pre-research demonstrates that VR environment offers a means of creating model situations where people with the disorder can learn verbal skills and work with manifestations of anxiety in a more realistic environment than if they were working on those skills without using VR. Moreover, the available feedback provided the opportunity for users to realize their mistakes or weaknesses and see them from a different perspective. This then made it easier to work with the negative thoughts that are common to this group of people. The use of VR to subsequently relax and ease stress had a positive impact on the therapy and made it more effective.

In spite of the fact, that pre-research was conducted on a small sample of pensioners suffering from a social anxiety disorder focusing on the verbal area, it suggests that virtual reality can be helpful in peoples' healing process. To make a clear conclusion that virtual reality has some influence on CBT, it is necessary to apply the research to a larger sample of individuals. The extension of this pre-research is further planned. The limit of research is a small sample and the absence of a control group. These findings will focus on further research.

\section{Acknowledgments}

This paper was prepared with the support by grant no. IGA/FAI/2018/017 from Internal Grant Agency of Tomas Bata University in Zlin.

\section{References}

[1] Kim, Hesun Erin, Yeon-Ju Hong, Min-Kyeong Kim, Young Hoon Jung, Sunghyon Kyeong a Jae-Jin Kim (2017). Effectiveness of self-training using the mobile-based virtual reality program in patients with social anxiety disorder. Computers in Human Behavior. 2017, 614-619. DOI: 10.1016/j.chb.2017.04.017. ISSN 07475632. Available: http://linkinghub.elsevier.com/retrieve/pii/S0747563217302595

[2] Kosová, Jiřina (2010). What really works in anxiety disorders: add therapeutic exercises to therapeutic combinations. Psychiatry for practice. Solen, ISSN 1803-5272.

[3] Sobota, Branislav a František Hrozek (2013). Virtual reality and its technology. Ostrava: Datakon Znalosti. ISBN 978-80-248-3189-3.

[4] Martirosov, S[ergo] \& Kopecek, P[avel] (2017). Virtual Reality and its Influence on Training and Education Literature Review, Proceedings of the 28th DAAAM International Symposium, pp.0708- 0717, B. Katalinic (Ed.), Published by DAAAM International, ISBN 978-3-902734-11-2, ISSN 1726-9679, Vienna, Austria DOI: 10.2507/28th.daaam.proceedings. 100

[5] Dudková, Anna (2015). Anxiety as a diagnosis (set of publicist interviews). Brno, 2015. Bachelor thesis. Faculty of Social Studies, Masaryk University.

[6] New trends in the treatment of anxiety disorders. Postgraduate medicine [online]. Mladá fronta, 2014 [cit. 2018 05-12]. Available: https://zdravi.euro.cz/clanek/postgradualni-medicina/nove-trendy-v-lecbe-uzkostnych-poruch475776

[7] Praško, Ján, Jana Vyskočilová and Jana Prašková (2008). Social phobia and its treatment: a guide for people with social phobia. Prague: Galén, 2008. ISBN 978-80-7262-580-2.

[8] Social phobia, social anxiety disorder. Our info health [online]. Lunar Media [cit. 2018-05-15]. Available from: http://www.naseinfo.cz/psychologie/socialni-fobie-socialni-uzkostna-porucha\#ixzz5Etsd45PL

[9] Letamendi, Andrea M., Denise A. CHavira and Murray B. Stein (2009).. Issues in the Assessment of Social Phobia: A Review. 2009, 46(1), 13-24.

[10] Wells, Adrian and Sam Cartwright-Hatton (2004). A short form of the metacognitions questionnaire: properties of the MCQ-30. Behaviour Research and Therapy. 2004, 42(4), 385-396. DOI: 10.1016/S0005-7967(03)00147-5. ISSN 00057967. Available: http://linkinghub.elsevier.com/retrieve/pii/S0005796703001475 